\title{
Common Studies of National Height System in Latvia and Lithuania
}

\author{
Armands Celms ${ }^{1}$, Ilona Reḳe ${ }^{1}$, Jānis Kaminskis ${ }^{2},{ }^{1}$ Latvia University of Agriculture, ${ }^{2}$ Riga Technical \\ University
}

\begin{abstract}
Already after our independence in the nineties of the twentieth century, we used common height system - Baltic Normal height system 1977 (BHS 1977). Latter we have made big job for verification and modernization of our geodetic network in the frames of different international campaigns. There we always cooperating with Nordic countries in frames of Nordic Geodetic Commission (NKG). Also we have had sector programme between Denmark and Baltic countries about modernization of geodetic network. Already in that time we carried out common work in the field of gravity survey, levelling and GNSS observation. As European Union member states - Latvia and Lithuania have changed their national height systems to European Vertical Reference System realizations. Latest product of such efforts, we have freely available latest Nordic quasi-geoid model NKG2015, too. For studies of height network consistency in regional and international level we carry out GNSS observation campaigns and making comparison of the obtained survey results and computed ones from different geoid models, for example LV98, NKG2015, EGG2015 etc. In such way, we are making conclusions about quality of geodetic network and giving recommendation for the future work. The aim of the research is using GNSS measurements gain insight for methodology development of geodetic point height testing. To achieve the aim following tasks were set: 1) perform GNSS measurements of first order levelling network points in Latvia and Lithuania; 2) to do data processing to get station coordinates; 3 ) to compare point elevations. For GNSS measurements use for height determination it is very significantly to use advanced measuring technologies and verified data processing methodology. RMS errors describe high accuracy of performed measurements.
\end{abstract}

Keywords: vertical network, GNSS, geoid model, normal height.

\section{Introduction}

Already after our independence in the nineties of the twentieth century we used common height system - Baltic Normal height system 1977 (BHS 1977). Latter we have made big job for verification and modernization of our geodetic network in the frames of different international campaigns. First common international campaign for verification of our geodetic network should be mentioned Danish-Baltic sector program, which took place in all three countries [9]. There geodesists from Danish National Land survey - KMS shared their experience and gave recommendations for future works. Besides theoretical studies, there were done practical control measurements on first order levelling lines to control stability of benchmarks. There we always cooperating with Nordic countries in frames of Nordic Geodetic Commission (NKG). Also we have had sector programme between Denmark and Baltic countries about modernization of geodetic network. Already in that time we carried out common work in the field of gravity survey, levelling and GNSS observation. And as a latest product of such efforts we have freely available Nordic quasi-geoid model NKG2015. For studies of height network consistency in regional and international level we carry out GNSS observation campaigns and making comparison of the obtained survey results and computed ones from different geoid models, for example LV98, NKG2015, EGG2015 etc. In such way we can make conclusions about quality of geodetic network and make recommendation for the future work.

The heights between Baltic states in BHS 1977 were connected in united geodetic network. But since $1^{\text {st }}$ December 2014 in Latvia as a national height system finds the European Vertical Reference System realization in Latvia - Latvian Normal Height System 2000,5 (LHS-2000,5) [1]. Lithuania has changed their national height system to European Vertical Reference System realization in Lithuania Lithuanian height system LAS07 on January $1^{\text {st }}$, 2016. Approximately difference between the old (BHS 1977) and new height system (LAS07) in the middle of Lithuania is about $14 \mathrm{~cm}$. Estonia has changed their national height system to European Vertical Reference System realization on January $1^{\text {st }}$, 2018.

Nowadays the Global Navigation Satellite System (GNSS) offers more and more advantages. To gain insight for methodology development of geodetic point height testing using GNSS measurements authors did measurements of 13 first order levelling network points in the territory of Latvia and 5 first order levelling network points in the territory of Lithuania using GNSS method. This method was chosen because of their simplicity - using global positioning and calculating ellipsoidal coordinates it is possible to see the height difference control in height system datum point and regional main geodetic 
points [13]. On points where direct GNSS observations are not possible to do due to satellite invisibility there is still need for precise levelling works [5].

For precise geodetic GNSS measuring, it is necessary to have a precise quasigeoid model. Since $1^{\text {st }}$ December 2014 Latvian specialists have developed a new quasigeoid model LV'14 with $4 \mathrm{~cm}$ accuracy [12]. Lithuanian digital geoid model will be improved after completing the first and second order of geodetic vertical network, as well terrestrial gravity measurements. This will enable to derive normal height from ellipsoidal heights determined by GNSS and replace traditional levelling of lower orders [10].

The aim of the research is to gain insight for methodology development of geodetic point height testing using GNSS measurements. To achieve the aim following tasks were set: 1) perform GNSS measurements of first order levelling network in Latvia and Lithuania; 2) to do data processing to get station coordinates; 3 ) to compare point elevations.

\section{Materials and Methods}

Establishment of Latvian National First Order Levelling Network has begun in 2000. Field measurements were finished in 2010 [3]. Geodetic measurements were made by the specialists of the Latvian State Land Service from 2000 till 2005 and Latvian Geospatial Information agency from 2006 till 2010. For the network establishment were used data of geodetic and gravimetric observations. The general requirement for not exceeding RMS error $0.5 \mathrm{~mm} / \mathrm{km}$ of the measured height differences was followed in the course of establishment of the National First Order Levelling Network [4].
Lithuanian National First Order Network (NGVN) establishment was going on from 1998 till 2007. Contracting authority for network establishment was National Land Service under the Ministry of Agriculture. The network consists of 5 loops in total of precise levelling lines [1].

Connection between Latvian and Lithuanian vertical networks was made in three places so connecting lines and constructing two first order levelling loops. The accuracy of Latvian and Lithuanian united levelling network in first iteration (standard deviation is $0.617 \mathrm{kgal} \times \mathrm{mm} / \mathrm{km}$ ) is at the same level as that of the vertical networks of biggest part of other countries participating in UELN project [1]. In 2008 Lithuania has also created two border connection points with Poland so connecting Lithuanian vertical network to European vertical network [11]. Now after national height systems' replacement from BHS 1977 to European Vertical Reference System realisations in Latvia and Lithuania the height connection between Latvia and Lithuania do not work [6].

For height determination traditionally were used precise levelling and nowadays mostly for measurements and height determination we also using GNSS as advanced instrument and new innovative technology. There are many opportunities to do studies on heights and compatibility between selected geodetic points. Very suitable instrument for studies or research on geodetic consistency is homogenous quasi-geoid or geoid model over decided area. On our case we found suitable geoid model LV98 (Fig. 1.) for this purpose. Geoid model LV98 were used in Latvia till December $1^{\text {st }}, 2014$. In the future we are planning to introduce also NKG2015 geoid for validation and verification of geodetic network [12].

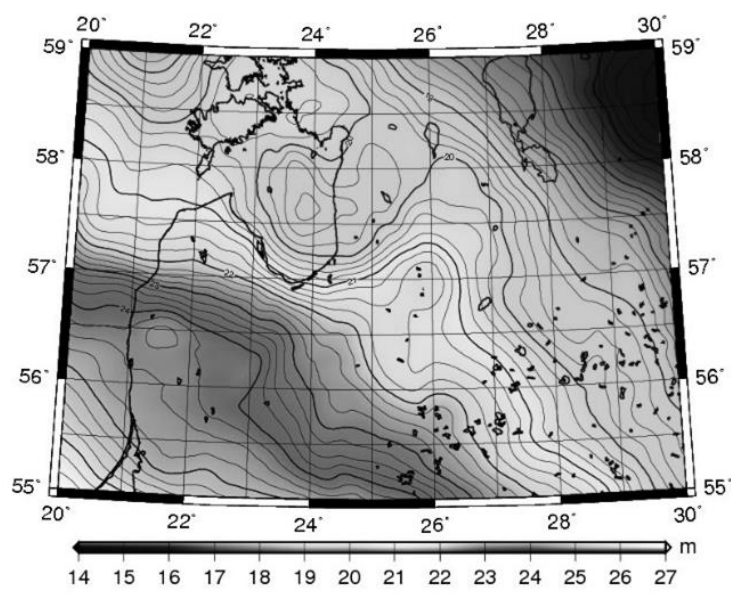

Fig. 1. Geoid model LV98 for territory of Latvia and Lithuania (source: authors'drawing).

As the first work for the GNSS measurements was the national geodetic network point inspection. There were some possible points selected and then visited on site to detect for each point the horizon above point and possibility to use GNSS methods for its height determination, also the point location conformity to point sketch. On the point were done global positioning real time measurements to detect the 
location of satellites above point. The requirement of open area is 20 degrees and for GNSS measurement PDOP should be at least 4 satellites. From the inspected points there were thirteen $1^{\text {st }}$ class levelling network points chosen as an appropriate geodetic point for GNSS measurements - ground marks 1415,
$1001,37,1155,1537,1636,1676,1727,8248$ and fundamental marks 1484, 0608, 3389 and 1463. In Lithuania were measured following first order geodetic points: ground marks 44V-988, 74V10308, 63V-01, 52V10013 and 74V10389 (Fig. 2).

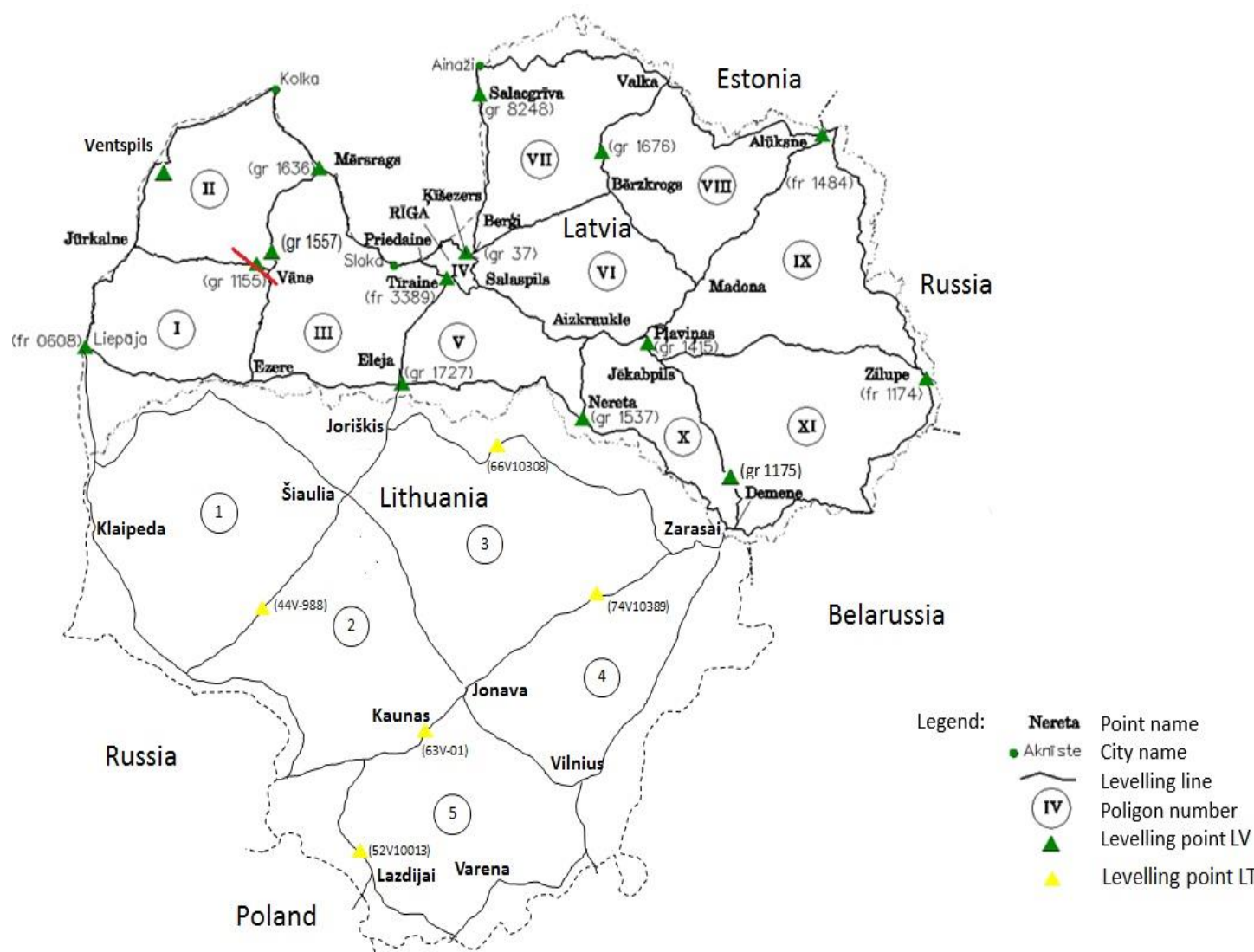

Fig. 2. Performed GNSS measurements in $1^{\text {st }}$ class levelling network of Latvia and Lithuania (source: authors' drawing).

The involved specialists in this project were form Latvian University of Agriculture, Riga Technical University, Latvia University, Aleksandras Stulginskis University, Kaunas Technical University and some private companies form Latvia. The main idea was to perform GNSS measurements on all selected points in the same time using global positioning in post-processing mode so providing avoidance from some errors.

Three years were performed 3 measurement sessions of Latvian first order levelling network $-14^{\text {th }}$ December 2012, 22 $2^{\text {th }}$ November 2013 and $27^{\text {th }}$ November 2014. On June $30^{\text {th }}$, 2016 were performed $4^{\text {th }}$ session and additionally involved experts from Lithuania. In this session in the same time were measured 13 first order levelling points in Latvia and 5 first order levelling points in Lithuania (Fig. 2.).

In measuring sessions from 2012 - 2014 the GNSS measurement has taken at least 4 hours long in the morning about 10 to 14 o'clock in Latvia Positioning System Base Station (LatPOS) network. LatPos is GNSS continuously operating network of Latvia [6]. On each first class levelling network point was installed GNSS receiver - Leica, Trimble, Topcon or GeoMax receiver - and 4 hours long collected GNSS data. In 2016 the duration of measurements was 5 hours in early morning about 6 to 11 o'clock in LatPOS network and Lithuania Positioning System Base Station (LitPOS) network.

After measuring for precise data processing and adjustment there were collected data from 3 nearest LatPOS or LitPOS base stations. The data from GNSS receivers and LatPOS/LitPOS stations were used for data adjustment and point height determination [15].

GNSS collected data were processed and analyzed by authors using academic software package Bernese GNSS Software (Version 5.2). There were raised following requirements for data processing: cut off angle - 20 degrees above horizon, precise ephemerides, NGS antenna calibration models, closest vector selection and free network adjustment.

\section{Results and Discussion}

For GNSS data processing was used software Bernese GNSS Software version 5.2. Reference 
points were selected 9 EPN (EUREF permanent network) stations: BOR1, GLSV, MAR6, ONSA, Riga, LAMA, LAMA, JOEN, PULK, VLNS.

All stations on $30^{\text {th }}$ of June 2016 assigned to Class A. For input data were used satellite ephemerides, the Earth's rotation parameters, ionosphere model and code shift (differential Code Biases (DCB)).

In the first processing step reference stations were converted to the day when the observations were made using the rates of IGB08.vel file. International GNSS Service (IGS) reference surface IGb08 is partial (incomplete) update the previous version IGS08. Several IGS08 station unusable observation failure and other operational reasons. IGb08 goal is to provide a reference surface.

Vectors were generated using automatic baseline creation options OBS-MAX. This option automatically generates vectors after the maximum number of common observation. The first option is calculated on the estimated float solution. Then it is calculated uncertainties. Uncertainty was calculated based on all approaches to the methods offered by the software Bernese v 5.2: after the phase-based Widelane (WL) uncertainties (vectors shorter than 200 $\mathrm{km}$ ), Phase-Based Wide-lane (L5) Ambiguity Resolution $(<200 \mathrm{~km})$, after the phase-based Narrowlane (NL) uncertainties (vectors shorter about 200 $\mathrm{km}$ ) and quasi-free ionosphere strategies (QIF). Treatment was performed using 3-degree angle. After the uncertainty of estimates is calculated using the final solution "free constraint solution" option. The minimum amount of constraint solution - define the Geodetic datum of the site coordinates using Network Conditions [8].

Each station is identified by one of the notes in the "e / f/h". This means e - estimated station coordinates (and / or rates are calculated), f - FIXED: Fixed Station with its "a priori" values $\mathrm{h}$ - HELMR: Station measured and used to determine the limits of e ECCEN: Applies the eccenter station.

The next calculations of coordinates and velocity determination of each station or any network restrictions.

It should be noted that the day-long session with the selected item spacing 2 hours, $12+1=13$ parameters. 2017 measurement processing for 2016 used a 1-hour interval.

A priori tropospheric model and global mapping function - DRY GMF is used in conjunction with the "wet" mapping function WET_GMF Computation of the partial derivatives of the troposphere zenith delay parameters (not for the a priori troposphere model). Gradient adjustment model - CHENHER. (Chen and Herring). Relative tropospheric zenith delay is equal to $5 \mathrm{~m}$ [7].

At the processing stations may choose station to be excluded from the assessment of the troposphere. This is necessary to choose the relative tropospheric modelling for small networks. Tropospheric parameters are summarized in file and applicate to stations for which data are available in the troposphere

TABLE 1

Station coordinates and evaluation (reference epoch 2016-06-30 12:00:00) (Source: construction by authors)

\begin{tabular}{|c|c|c|c|c|c|c|c|}
\hline Station & Name & $\begin{array}{c}N \\
{[G G . G G G G G G]}\end{array}$ & $\begin{array}{c}E \\
{[G G . G G G G G G]}\end{array}$ & $U[m]$ & $\begin{array}{c}\text { RMS } \\
\text { error } \\
(N)[m]\end{array}$ & $\begin{array}{l}R M S \\
\text { error } \\
(E)[m]\end{array}$ & $\begin{array}{c}R M S \\
\text { error } \\
(U)[m]\end{array}$ \\
\hline 37 & 3700001 & 57.008253 & 24.244461 & 27.753 & 0.001 & 0.002 & 0.003 \\
\hline 677 & 67700001 & 55.387412 & 25.056543 & 150.839 & 0.002 & 0.002 & 0.006 \\
\hline 1026 & 102600001 & 57.684461 & 22.317175 & 24.718 & 0.001 & 0.001 & 0.004 \\
\hline 1175 & 117500001 & 55.738400 & 26.679104 & 175.516 & 0.001 & 0.001 & 0.002 \\
\hline 1415 & 141500001 & 56.585332 & 25.778344 & 98.174 & 0.001 & 0.001 & 0.003 \\
\hline 1463 & 146300001 & 57.012043 & 21.390681 & 35.848 & 0.001 & 0.001 & 0.005 \\
\hline 1537 & 153700001 & 56.252400 & 25.216775 & 101.930 & 0.001 & 0.001 & 0.004 \\
\hline 1557 & 155700001 & 56.946010 & 22.602501 & 104.316 & 0.001 & 0.001 & 0.004 \\
\hline 1636 & 163600001 & 57.385169 & 22.972672 & 27.534 & 0.001 & 0.001 & 0.005 \\
\hline 1676 & 167600001 & 57.454856 & 25.421595 & 78.702 & 0.001 & 0.001 & 0.004 \\
\hline 1727 & 172700001 & 56.415087 & 23.696916 & 55.308 & 0.001 & 0.001 & 0.004 \\
\hline 5770 & 577000001 & 55.429877 & 22.628199 & 137.163 & 0.001 & 0.001 & 0.004 \\
\hline BOR1 & $12205 \mathrm{M} 002$ & 52.276958 & 17.073460 & 124.359 & 0.000 & 0.000 & 0.001 \\
\hline GLSV & 12356M001 & 50.364184 & 30.496736 & 226.313 & 0.000 & 0.000 & 0.001 \\
\hline JOEN & $10512 \mathrm{M} 001$ & 62.391175 & 30.096163 & 113.795 & 0.000 & 0.000 & 0.001 \\
\hline KAUN & KAUN00001 & 54.877735 & 24.005481 & 60.785 & 0.002 & 0.002 & 0.006 \\
\hline LAMA & 12209M001 & 53.892402 & 20.669945 & 187.032 & 0.000 & 0.000 & 0.001 \\
\hline MAR6 & 10405M002 & 60.595145 & 17.258530 & 75.533 & 0.000 & 0.000 & 0.001 \\
\hline ONSA & 10402M004 & 57.395300 & 11.925521 & 45.608 & 0.000 & 0.000 & 0.001 \\
\hline PEDE & PEDE00001 & 57.494531 & 27.338593 & 176.513 & 0.002 & 0.002 & 0.008 \\
\hline PULK & $12305 \mathrm{M} 001$ & 59.771840 & 30.327787 & 101.170 & 0.000 & 0.000 & 0.001 \\
\hline RIGA & 12302M002 & 56.948621 & 24.058778 & 34.727 & 0.000 & 0.000 & 0.001 \\
\hline VLNS & 10801M001 & 54.653144 & 25.298673 & 240.843 & 0.000 & 0.000 & 0.001 \\
\hline ZILU & ZILU00001 & 56.370086 & 28.118101 & 158.208 & 0.001 & 0.001 & 0.003 \\
\hline
\end{tabular}


Each of the 24 surveyed stations are calculated using tropospheric parameters of Latvian and Lithuanian territory. The points were calculated referencing 9 EPN stations (BOR1, GLSV, JOEN, LAMA, MAR6, ONSA, PULK, RIGA, VLNS) in epoch 30.06.2016. (using velocity file (*.vel) for reference stations). As input data were used code shifting (P1C11606.DCB, P1P21606.DCB), Earth rotation parameters (COD19037.ERP), precise orbits (COD19034.EPH) and ionospheric model (COD19034.ION). The point evaluation of the North and East values is less than $2 \mathrm{~mm}$. Height component average value is approximately $3 \mathrm{~mm}$, and in some points it reaches 6 and $8 \mathrm{~mm}$ (677, KAUN and PEDE).

About correct geodetic data there is common ongoing activities within Nordic Geodetic Commission (NKG) for compatible local geoid model all over region. Very essential for good results is to use correct or accurate geodetic data. For modelling also gravity data should be verified or cross validated between different survey campaigns and sources [14]. It is great contribution for new NKG2015 geoid model over region, which was released during gravity field meeting International Symposium on Gravity, Geoid and Height Systems 2016 Thessaloniki, Greece on 19 - 23 September 2016. Also selected GNSS and levelling nodal or reference points from every country are used for control or accuracy estimation from official NKG database. Usually in database countries store the best available geodetic data for research and development of new applications.

\section{Conclusions}

For such GNSS measurement project successful organization it is very necessary to do previous preparation and critical situation analysis. Also performing GNSS measurements in the same time in the territory of Latvia and Lithuania the experience of mutual cross-border cooperation is accumulated.
For GNSS measurement height determination it is very significantly to use advanced measuring technologies and verified data processing methodology. There we can use some knowledge from classical geodetic - astronomical approach that is rather independent method for height network validation.

Performed measurements have a high accuracy which describes RMS errors. Average error value for axis $\mathrm{N}$ and $\mathrm{E}$ is $0.001 \mathrm{~m}$, but measurement height component average error value is $0.003 \mathrm{~m}$.

The results obtained from GNSS measurements can be used for height system and geoid model conformity assessment in Baltic region. In connection with geoid model significance to geodetic result data precision, it is desirable to perform GNSS measurements of I class levelling networks in Latvia, Lithuania and Estonia. This way it can verify and test geoid model on larger areas thereby getting certainty about geoid model precision. I class geodetic network between Lithuania, Latvia and Estonia are physically levelled or directly connected. We can recommend for near future to use revitalizing method from classical geodesy coming from times before GPS was used. In this, we use digital zenith camera for deflection of vertical (DoV) measurements. It is like to use together knowledge of astronomy and geodesy as independent control for levelling, gravity and ellipsoidal heights from GPS observations. It is very useful to perform DoV observations on many control/nodal points in Lithuania and Latvia, as well in future also in Estonia, especially on islands. It will help to increase accuracy for geoid model on land and on sea. If the geoid model accuracy will increase (to $2 \mathrm{~cm}$ ) the validity of calculated height values also will increase.

\section{Acknowledgements}

The research was supported by project "Strengthening Research Capacity in the Latvia University of Agriculture".

\section{References}

1. Aleksejenko, I., Kaminskis, J., Sakne, J., et al. Levelling network Connection Between Latvia and Lithuania. Enivronmental Engineering, Lithuania: Vilnius Gediminas Technical University, 2011, p. 1269-1278.

2. Celms, A., Bimane I., Reke I. European Vertical Reference System in Baltic Countries. Baltic Surveying, 2014 , No. 1 (8), p. 49-55.

3. Celms, A., Kaminskis, J. Levelling results of first order line Kolka - Rucava. Baltic Surveying '05, 2005, Latvia: Latvia University of Agriculture, p. 165-170.

4. Celms, A., Kronbergs, M., Cintina, V. Accuracy Estimation of the Latvia First Order levelling Network. GEOFORUM, 2012, No.1, p. $44-47$.

5. Celms, A., Kronbergs, M., Cintina V., et al. Precision of Latvia Levelling Network Nodal Point Height. CIVIL ENGINEERING, 2013, No. 4, p. 310-317.

6. Celms A, Reke I., Ratkevics A. European Vertical Reference System Influence in Latvia. Innovative Materials, Structures and Technologies, 2015 p. 30-37.

7. Dach, R., Jean, Y. Technical Report. (2012) International GNSS Service. [online 15.03.2017.]. ftp://igs.org/pub/resource/pubs/2012_techreport.pdf.

8. Dach, R.,, Lutz, S., Walser, P., et al. Bernese GNSS Software. Version5.2. Astronomical Institute, Universituy of Bern, 2015.

9. Ellmann A., Torim A., Abols N., et al. Different solutions adopted to modernize the height networks in the Baltic countries. The importance of Heights Proc. "Geodesy and Surveying in the future", March 15-17, 1999, Gavle, Sweden, p. 349-360.

10. Krikštaponis, B., Paršeliūnas, E. K., Viskontas, P., et al. Designing issues of the geodetic vertical reference network of Lithuania. Environmental Engineering, 2014, p. 1-10. 
International Scientific Conference "RESEARCH FOR ENVIRONMENT AND CIVIL ENGINEERING DEVELOPMENT 17" Proceedings “CIVIL ENGINEERING” 17"

11. Krikštaponis, B., Tumeliene, E. Development of Lithuanian National Geodetic Vertical First Order Network. Environmental Engineering, 2011 p. 1362-1369.

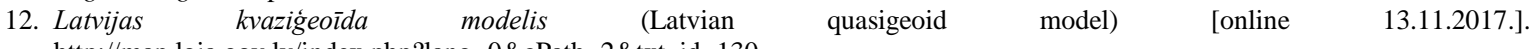
http://map.lgia.gov.lv/index.php?lang=0\&cPath=2\&txt_id=130

13. Lazdans, J., Aleksejenko, I., Kaminskis, J., et al. Aktualitāte Latvijas sasaistē ar Eiropas augstumu sistēmu (Current Events Latvia Connecting with European Height System). Latvia University Scientific conference No.67, 2009.

14. Märdla, S., Ågren, J., Strykowski, G., et al. From Discrete Gravity Survey Data to a High-resolution Gravity Field Representation in the Nordic-Baltic Region. Marine Geodesy, 2017, 40, p. 416 - 453.

15. Reiniks, M., Lazdans, J., Ratkus, B. Valsts augstuma izejas līmeņa noteikšana (Determination of state height datum level). Riga Technical University scientific articles. No.7, p 7-13. 